\title{
O Estágio Supervisionado de Geografia em Unidades de Conservação: experiências no Parque Municipal da Lagoa do Peri - Florianópolis/SC
}

\author{
Supervised Internship of Geography in Conservation Units: \\ experiences at Lagoa do Peri Municipal Park - Florianópolis/SC
}

Prácticas Supervisadas de Geografía en Unidades de Conservación: experiencia en el Parque Municipal Lagoa do Peri - Florianópolis/SC

Ana Paula Nunes Chaves ${ }^{1}$

\begin{abstract}
RESUMO: O presente artigo tem como objetivo discutir as possibilidades de ensino em espaços não formais de educação por meio de experiências formativas no Parque Municipal da Lagoa do Peri, uma das nove unidades de conservação localizadas na cidade de Florianópolis/SC. A pesquisa contou com a participação de estudantes da 7 a fase do curso de Geografia Licenciatura da UDESC, vinculados à disciplina de Estágio Curricular Supervisionado em Geografia III, no primeiro semestre de 2018. As atividades foram conduzidas em duas etapas complementares: foram realizados estudos bibliográficos acerca do parque e trabalhos de campo apoiados em observação e entrevistas em um período de dois meses. Divididos em grupos, os estudantes planejaram e desenvolveram dois projetos: um roteiro de saída de estudos na trilha Caminho do Saquinho, e um curta-metragem com o intuito de problematizar a temática do lixo e dos resíduos sólidos na comunidade do Sertão do Ribeirão (popularmente conhecido como Sertão do Peri), núcleo de população tradicional residente no parque. Os projetos desenvolvidos abriram novas possibilidades de conhecimento para comunidade local e criaram novas perspectivas de intercâmbio acadêmico entre a universidade e o parque. Ademais, deram visibilidade à promoção de ações educativas de diferentes naturezas, bem como o incentivo à formação docente em unidades de conservação.
\end{abstract}

PALAVRAS-CHAVE: Estágio supervisionado em Geografia. Formação docente em unidades de conservação. Parque Municipal da Lagoa do Peri.

ABSTRACT: This article aims to discuss the possibilities of teaching in non-formal spaces of education through formative experiences in the Lagoa do Peri Municipal Park, one of nine Conservation Units located in the city of Florianópolis/SC. The research was attended by students from the 7th phase of the UDESC Geography course, linked to the Supervised Curricular Internship Geography III discipline, in the first semester of 2018. The activities were conducted in two complementary stages: bibliographic studies were carried out about the Park and fieldwork supported by observation and interviews over a period of two months. Divided into groups, the students planned

\footnotetext{
1 Universidade do Estado de Santa Catarina - UDESC. Av. Madre Benvenuta, 2007 - Bairro Itacorubi Florianópolis, Santa Catarina, Brasil - CEP: 88.035-001. ana.chaves@udesc.br.
} 
and developed two projects: a roadmap for studies on the Caminho do Saquinho trail, and a short film to discuss the theme of garbage and solid waste in the community of Sertão do Ribeirão (popularly known as Sertão do Peri), core of the traditional resident population of the park. The projects developed opened new knowledge possibilities for the local community and created new perspectives for academic exchange between the university and the park. In addition, they gave visibility to the promotion of educational actions of different natures, as well as the encouragement of teacher training in conservation units.

KEYWORDS: Internship supervised in Geography. Teacher training in conservation units. Lagoa of Peri Municipal Park.

RESUMEN: Este artículo tiene como objetivo discutir las posibilidades de enseñanza en espacios no formales de educación a través de experiencias formativas en el Parque Municipal Lagoa do Peri, una de las nueve unidades de conservación ubicadas en la ciudad de Florianópolis/SC. A la investigación asistieron estudiantes de la séptima fase del curso de Geografía de la UDESC, vinculada a la disciplina de Pasantía Curricular Supervisada en Geografía III, en el primer semestre de 2018. Las actividades se llevaron a cabo en dos etapas complementarias: se realizaron estudios bibliográficos sobre del Parque y trabajos de campo apoyados por observación y entrevistas durante un período de dos meses. Divididos en grupos, los estudiantes planearon y desarrollaron dos proyectos: una ruta para estudios sobre el sendero Caminho do Saquinho, y un cortometraje para discutir el tema de la basura y los desechos sólidos en la comunidad de Sertão do Ribeirão (popularmente conocido como Sertão do Peri), núcleo de la población tradicional residente del parque. Los proyectos desarrollados abrieron nuevas posibilidades de conocimiento para la comunidad local y crearon nuevas perspectivas de intercambio académico entre la universidad y el parque. Además, dieron visibilidad a la promoción de acciones educativas de diferentes naturalezas, así como al fomento a la formación docente en unidades de conservación.

PALABRAS-CLAVE: Prácticas supervisadas en Geografía. Formación docente en unidades de conservación. Parque Municipal Lagoa do Peri.

\section{INTRODUÇÃO}

O Parque Municipal da Lagoa do Peri é a maior unidade de conservação de Florianópolis e sua importância se deve, principalmente, à presença do maior reservatório de água doce do litoral catarinense. Foi criado em 1981 pela Lei Municipal 1.828 e abrange uma área de 20,3 quilômetros quadrados sendo, em média, um quarto correspondente à lâmina d'água (IPUF, 1978). Daí decorre seu primeiro objetivo, a proteção do manancial hídrico da bacia da Lagoa do Peri (Figura 1). Além deste propósito, o parque também busca preservar o patrimônio natural representado pela fauna e flora; propiciar o desenvolvimento social da comunidade nativa; e desenvolver atividades educativas, de lazer e recreação (FLORIANÓPOLIS, 1981).

Embora façamos o uso da denominação da unidade de conservação como um parque, é importante ressaltar que durante a realização e finalização deste trabalho o parque passou por uma nova recategorização para atender a Lei Federal n 9.985 (BRASIL, 2000), do Sistema Nacional de Unidades de Conservação da Natureza - SNUC. Assim, conforme a Lei 
Municipal 10.530 (FLORIANÓPOLIS, 2019), o Parque passa a ser classificado como Monumento Natural e será denominado Monumento Natural Municipal da Lagoa do Peri MONA da Lagoa do Peri.

Figura 1 - Ilha de Santa Catarina, com destaque para a Lagoa do Peri ao centro

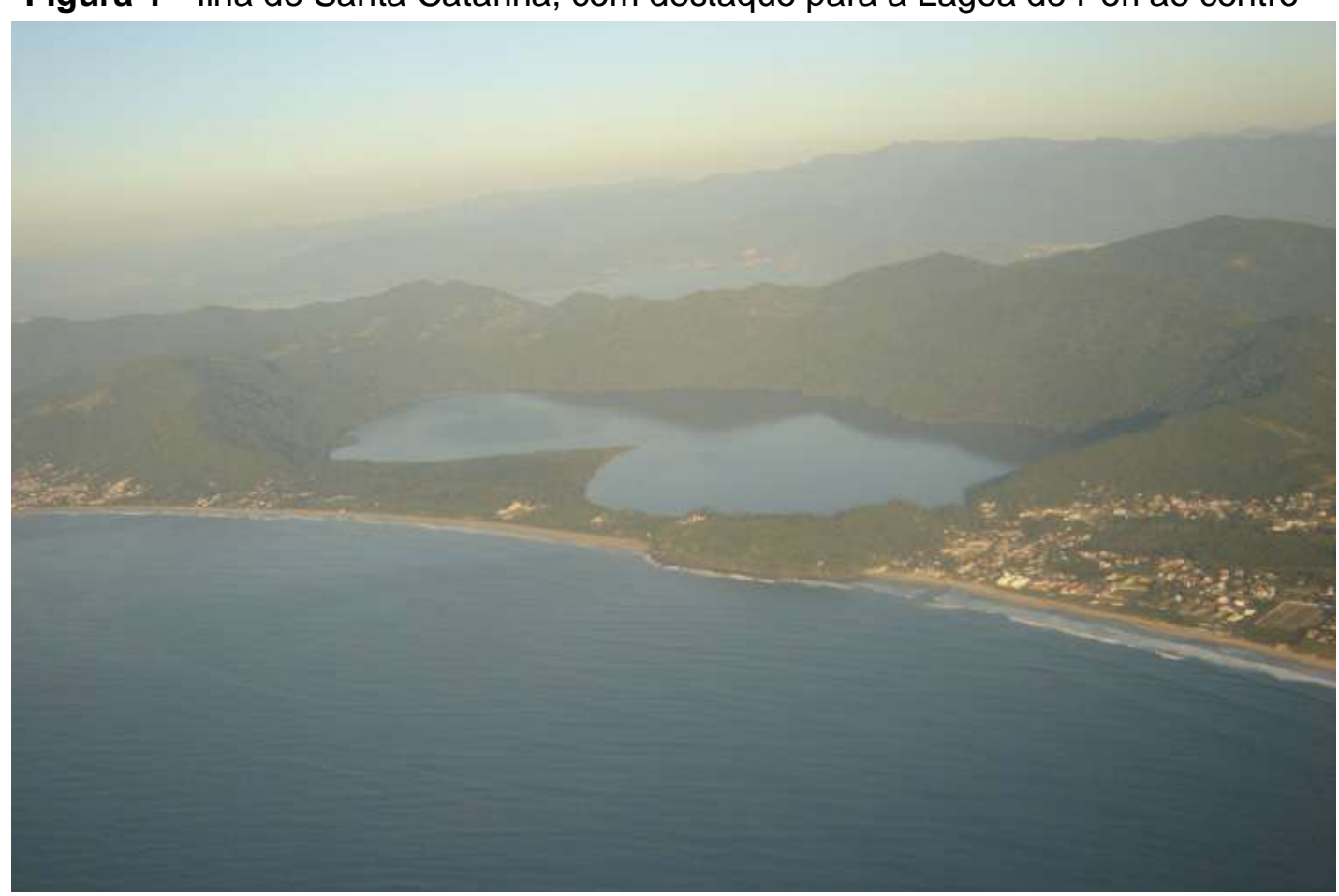

Fonte: DEPUC (2018).

A escolha desta unidade de conservação para a realização da pesquisa deve-se, principalmente, pela tamanha expressividade desse espaço público, tanto pela exposição de suas paisagens que the conferem ampla e legítima visibilidade, quanto pelo potencial geoturístico, com um número de frequentadores que ultrapassa a marca de 2.000 pessoas diárias durante o verão (STEPANSKI, 2014).

Em dezembro de 2015 o Parque Municipal da Lagoa do Peri recebeu a Bandeira Azul, símbolo internacional de certificação de qualidade conferido a praias em diversos países. $O$ Programa Bandeira Azul, da Foundation for Environmental Education, surgiu na França em 1985 e está presente em 49 países. Dentre os critérios de qualidade que garantiram a certificação ao parque constam: atividades de educação ambiental, centro de visitantes, placas informativas, comitê gestor da praia, recipientes adequados ao lixo e fonte de água potável, dentre outros. Considerando a larga repercussão e reverberação das dinâmicas geoturísticas e geoeducativas ali existentes, a formação docente em unidades de conservação como esta pode corroborar para garantir a proteção de paisagens que apresentam características naturais e culturais proeminentes. 
Se, por um lado, atualmente conferimos a promoção de paisagens que tornam o parque um dos principais pontos de visitação de Florianópolis, por outro persistem problemas de ordem morfológica, territorial, institucional e educativa que expõem conflitos e a falta de convergência de interesses sociais e públicos. Os conflitos de ordem educativa se associam à grande procura dos espaços e sua incipiente estrutura na promoção de atividades educativas e ambiental, em especial nas trilhas que cruzam as zonas de reserva biológica. Em relação a este último aspecto, ainda que a Bandeira Azul tenha conferido certificação qualificada ao parque, principalmente em virtude das atividades de educação ambiental, conferimos certo distanciamento do que se propõe em legislação e o que realmente é executado.

Dessa maneira, o presente artigo tem como objetivo discutir as possibilidades de ensino em espaços não formais de educação por meio de experiências formativas no Parque Municipal da Lagoa do Peri, localizado ao sul da llha de Santa Catarina, na cidade de Florianópolis. Para tanto, a pesquisa contou com a participação de estudantes da $7^{\underline{a}}$ fase do curso de Geografia Licenciatura da Universidade do Estado de Santa Catarina - UDESC, vinculados à disciplina de Estágio Curricular Supervisionado em Geografia III.

\section{O PARQUE E SUAS PAISAGENS}

O Parque Municipal da Lagoa do Peri (Figura 2) é dividido em três grandes áreas: a Área de Reserva Biológica, a Área de Paisagem Cultural e a Área de Lazer. De acordo com o Plano Diretor de ocupação e uso do solo do Parque (FLORIANÓPOLIS, 1982), a Área de Reserva Biológica é uma área de preservação integral e permanente do ecossistema e de seus recursos, com uso permitido somente para fins científicos e educativos. A Área de Paisagem Cultural é a porção do território onde se localizam os assentamentos e atividades associadas aos descendentes de antigos colonizadores açorianos. Localmente denominada de Sertão do Peri ou Sertão do Ribeirão, abriga atividades tradicionais como a produção de cachaça e farinha nos engenhos e atividades de agricultura de subsistência de caráter artesanal. Já a Área de Lazer compreende a planície de restinga com o acúmulo de sedimentos arenosos e recentes que separam a lagoa do mar. Nesta área encontra-se a maior diversidade de instrumentos urbanos, dentre eles a sede administrativa do parque, instituições de ensino e pesquisa, domicílios, organizações religiosas, sede de associações comunitárias e a estação de captação e tratamento de água da Companhia Catarinense de Águas e Saneamento (CASAN).

Apesar de considerada uma das mais importantes Unidades de Conservação (UC) de Proteção Integral no município, desde meados do século XVIII as ações humanas interferem de modo diverso na dinâmica do local, seja na proteção legal do patrimônio paisagístico 
(FLORIANÓPOLIS, 1981), seja na exploração indiscriminada dos recursos (CABRAL, 1999). Segundo Sbroglia e Beltrame (2012), os conflitos que dificultam a gestão e o desenvolvimento dos objetivos propostos pelo parque, em grande medida, foram ocasionados pelo precário processo de implantação e pela omissão do Poder Público, principalmente durante seus primeiros anos de existência.

Figura 2 - Mapa de localização do Parque Municipal da Lagoa do Peri

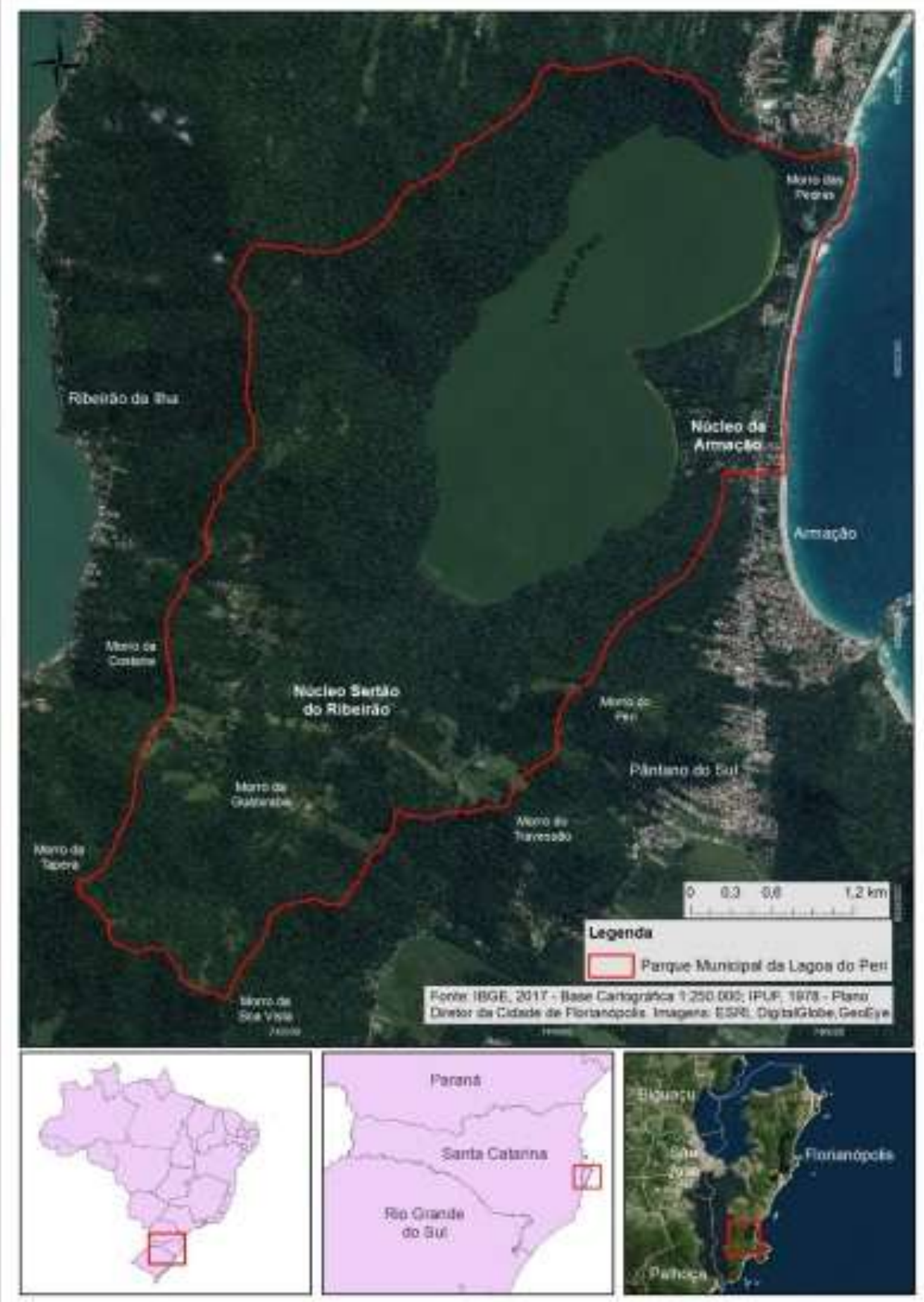

Fonte: Câmara (2018). 
Ao longo de três séculos a colonização portuguesa-açoriana na llha de Santa Catarina foi responsável por descaracterizar significativamente a paisagem fitogeográfica e os processos de sucessão ecológica, relegando a cobertura vegetal atual a uma imagem reduzida do que fora no passado. Ainda que haja no parque pequenas áreas remanescentes em meio às formações arbóreas secundárias (capoeirões), apenas uma única área de maior expressividade encontra-se em um vale próximo a Lagoa do Peri (KLEIN, 1984). Nos primeiros anos de existência do parque o extrativismo vegetal decorria, principalmente, da extração de lenha para manutenção dos engenhos, aliada à coivara praticada pelos habitantes do Sertão do Ribeirão. Além disso, houve a extração de palmito içara, extrativismo de cipó, plantas fitoterápicas e o chamado desmatamento seletivo (SBROGLIA; BELTRAME, 2012).

A área do parque é formada pelo bioma Mata Atlântica nas suas formações: floresta ombrófila densa, restinga e as comunidades aluviais (neste caso, lacustres). As formações pioneiras, por estarem em terrenos mais planos e próximos ao litoral, foram as que mais sofreram processo de retirada de espécies nativas antes da implantação da UC. Parte da restinga foi utilizada para silvicultura, com plantios de espécies exóticas, como o pinus elliottii e o eucaliptus. Outras espécies introduzidas pela atividade agrícola, anterior a UC, ainda resistem à sucessão ecológica atual. Dentre as espécies exóticas observadas in loco nos anos de 2015 e 2016, além de pinos e eucaliptos, encontramos bambus, castanheiras e cafezais. Já entre as espécies animais, a presença de saguis (Callithrix spp.) e da tilápia (Tilapiarendalli) afetam drasticamente os ecossistemas do parque.

A ocupação do Parque Municipal da Lagoa do Peri originou-se a partir da Freguesia de Nossa Senhora da Lapa do Ribeirão, núcleo de colonização açoriana instalado na região no século XVIII. Segundo Cabral e Buss (2002), dois sítios de ocupação se estabeleceram: um, nas partes elevadas do sul da bacia (hoje Sertão do Ribeirão), onde a agricultura (mandioca, cana-de-açúcar, café, milho e feijão) e a manufatura de engenho predominavam; o outro, na planície de restinga da face leste, onde as atividades produtivas conjugavam pesca e agricultura.

Embora a comunidade do Sertão do Ribeirão esteja assegurada pelo Decreto Municipal ํo. 091/82 em seu Art. 28, permitindo nesta área usos públicos de interesse social e as atividades agrícolas, zootécnicas e de transformação artesanal tradicionais, compatíveis com a preservação do ambiente natural, a implantação do parque e o declínio de atividades agrícolas colaboraram sobremaneira para a decadência da cultura local. A partir de meados do século XX as atividades tradicionais declinam cada vez mais, pois a agricultura de subsistência das famílias foi paulatinamente conjugada, ou verdadeiramente substituída, por atividades relacionadas à expansão urbano-turística. 
Para Sbroglia e Beltrame (2012), o declínio das atividades também esteve associado à falta de amparo aos moradores tradicionais por parte dos órgãos gestores; à falta de assistência e alternativas para substituir e adaptar as atividades agrícolas desenvolvidas e à ação repressiva dos órgãos de proteção ambiental, principalmente devido aos conflitos gerados em torno do manejo de recursos naturais. Tal situação fez com que grande parte dos moradores abandonasse suas terras em busca de áreas urbanizadas. Dos 35 engenhos que existiam em funcionamento, em 2017 restaram apenas dois engenhos de farinha e três alambiques ainda em atividade. Uma redução brusca refletindo significativamente no aniquilamento da cultura local e na perda de territorialidades por parte da comunidade tradicional ali instalada, acentuando ainda mais o relativo isolamento da população restante.

\section{O PARQUE COMO LABORATÓRIO DE ENSINO}

Vislumbrando no parque múltiplas possibilidades de ensino e partindo do ensejo de estabelecer parcerias entre a universidade e a unidade de conservação, delineamos uma proposta de estágio para ser executada durante o primeiro semestre de 2018. A proposta abarcaria os estudantes da $7^{\underline{a}}$ fase do curso de Geografia Licenciatura, matriculados na disciplina Estágio Curricular Supervisionado em Geografia III. A disciplina, dentre seus propósitos, busca fomentar a formação do estudante de Geografia na pesquisa, planejamento e desenvolvimento de atividades de ensino em espaços não formais de educação. É uma disciplina relativamente jovem no curso de Geografia da Udesc, pois foi ofertada pela segunda vez em 2018. Além do professor orientador de estágio, as atividades em espaços não formais de educação contavam com o apoio de um geógrafo supervisor em campo. Assim, sete estudantes tiveram a oportunidade de estagiar no Parque Municipal da Lagoa do Peri.

As atividades foram conduzidas em duas etapas de trabalho complementares: a) a primeira destinou-se à organização e levantamentos iniciais das fontes bibliográficas e documentais acerca do parque, pesquisa realizada tanto na sede do parque como em bibliotecas universitárias; b) a segunda etapa esteve relacionada à pesquisa exploratória em trabalhos de campo. Nesta etapa, foram realizadas saídas de estudos semanais durante dois meses visando identificar elementos geográficos na paisagem que pudessem ser articulados aos conteúdos de Geografia na educação básica, bem como entrevistas com lideranças locais e funcionários do DEPUC.

Após este reconhecimento inicial do parque, os estudantes foram divididos em dois grupos. A proposta era que cada grupo pudesse planejar e desenvolver um projeto a partir dos conhecimentos adquiridos até então. Os projetos desenvolvidos foram acerca de um roteiro de saída de estudos no Caminho do Saquinho e um curta-metragem sobre a 
problemática do lixo e dos resíduos sólidos no Sertão do Ribeirão. A seguir, apresentamos cada uma das propostas.

\section{O Caminho do Saquinho no Parque Municipal da Lagoa do Peri como espaço de construção do saber geográfico}

O Caminho do Saquinho é uma das trilhas mais conhecidas e utilizadas pelos frequentadores do parque. Seu percurso está inserido tanto na Área de Lazer como na Área de Reserva Biológica. Por ser uma trilha de fácil acesso e próxima à sede do Parque, foi eleita pelos estudantes para a realização da atividade (Figura 3).

Figura 3 - Atividade na trilha Caminho do Saquinho

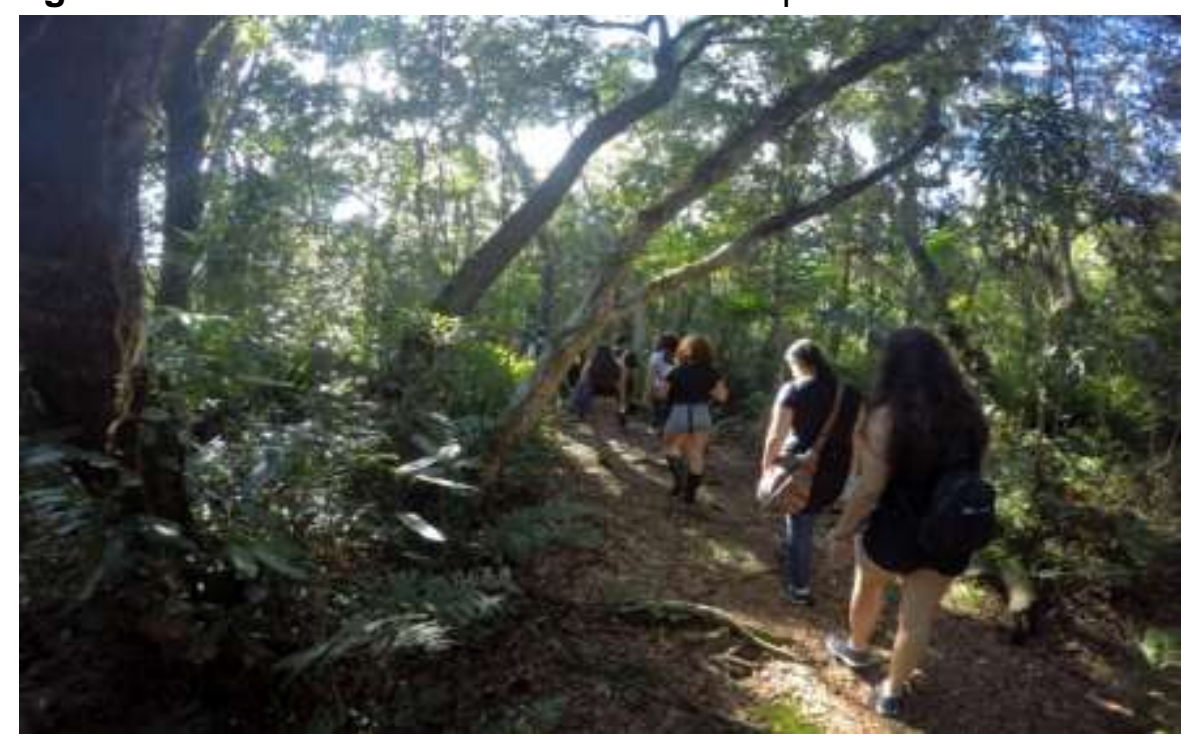

Fonte: elaborado por Matheus Sagaz (2018).

Diante do desejo de valorizar e dar visibilidade aos aspectos naturais e culturais presentes no parque, os estudantes elaboraram uma proposta de saída de estudos como subsídio teórico-metodológico para professores de Geografia da educação básica. A atividade, planejada para ser realizada em três horas, foi dividida em três momentos: uma apresentação geral do parque ao grupo de participantes, a trilha propriamente dita e o encerramento com uma roda de conversa às margens da Lagoa do Peri.

Foram selecionados 11 pontos ao longo da trilha (Figura 4). Os principais elementos destacados no roteiro dizem respeito à fauna e à flora local, tanto de espécies nativas quanto exóticas; às características morfológicas da paisagem, como o relevo, a composição do solo e a hidrologia presentes no Parque; e à paisagem cultural, conferida nos resquícios de antigos engenhos que se pressupõe serem de cachaça, devido ao declive em que foram construídos. 
Figura 4 - Pontos de estudos ao longo do Caminho do Saquinho

Conhecendo o Parque Municipal da Lagoa do Peri

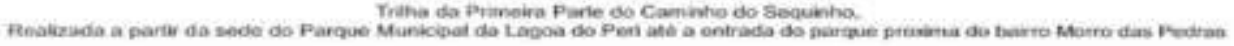

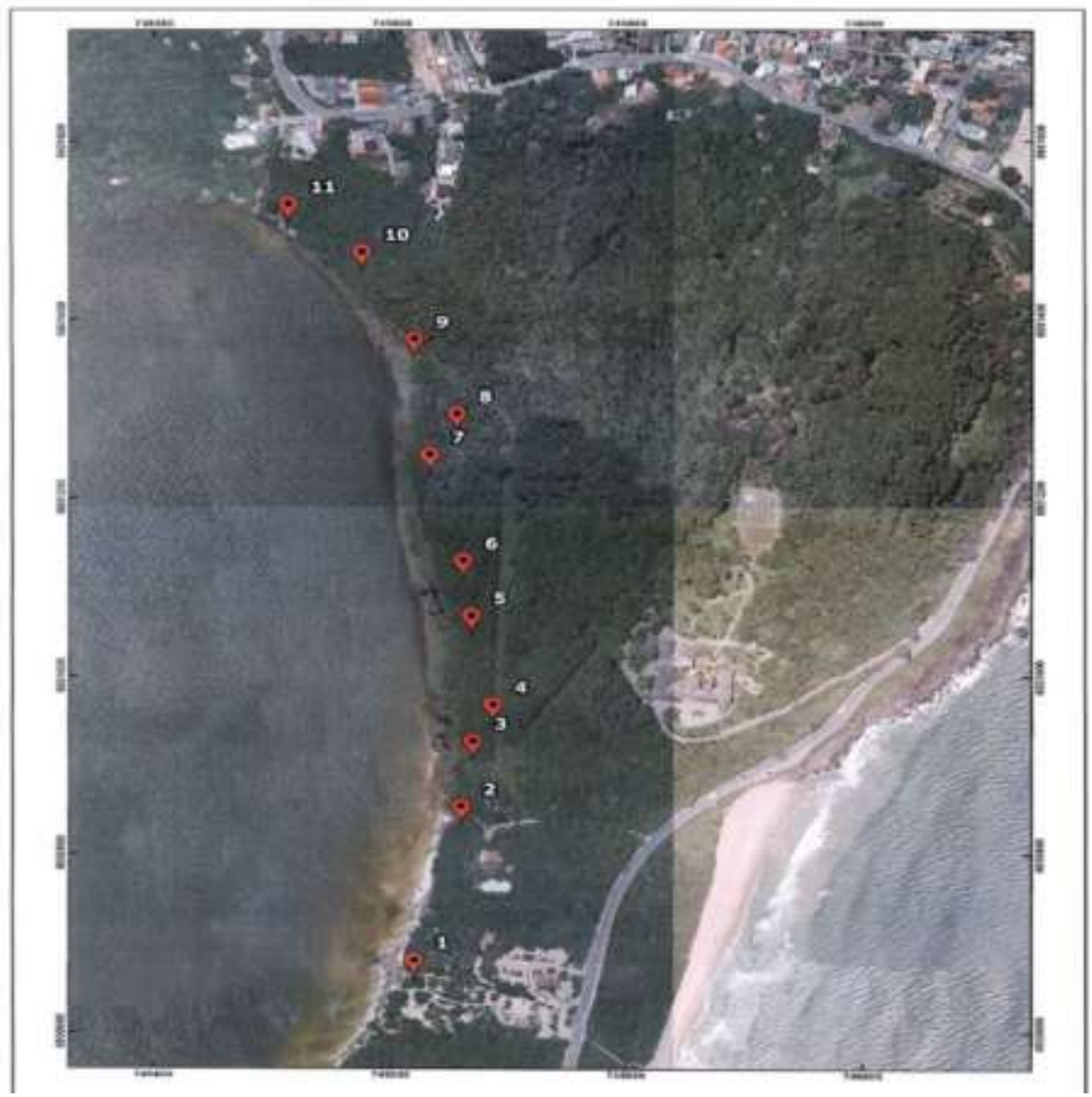

Fonte: elaborado por Matheus Sagaz (2018).

Ao longo do semestre, a saída de estudos, em formato de oficina, foi realizada com três grupos distintos: com os participantes da Semana da Faed/Udesc; com os estudantes da $3^{\underline{a}}$ fase da disciplina de Educação Ambiental do curso de Geografia da Udesc; e com os participantes do IV Encontro de Práticas de Ensino em Geografia da Região Sul - ENPEGSul.

Para onde vai o lixo? A luta da comunidade Sertão do Ribeirão na regularização da coleta

O segundo grupo trouxe à baila a problemática do lixo e dos resíduos sólidos no Sertão do Ribeirão, localizado na Área de Paisagem Cultural do parque. O ensejo em trabalhar com tal temática adveio de demandas da própria comunidade, em particular a preocupação com o descarte adequado do lixo e dos resíduos sólidos, e as dificuldades enfrentadas quanto à regularização da coleta do lixo (Figuras 5 e 6). Para tanto, o projeto 
desenvolvido resultou na produção de um curta-metragem com o intuito de problematizar e dar visibilidade ao tema em questão.

Figura 5 - Descarte do lixo no Sertão do Ribeirão

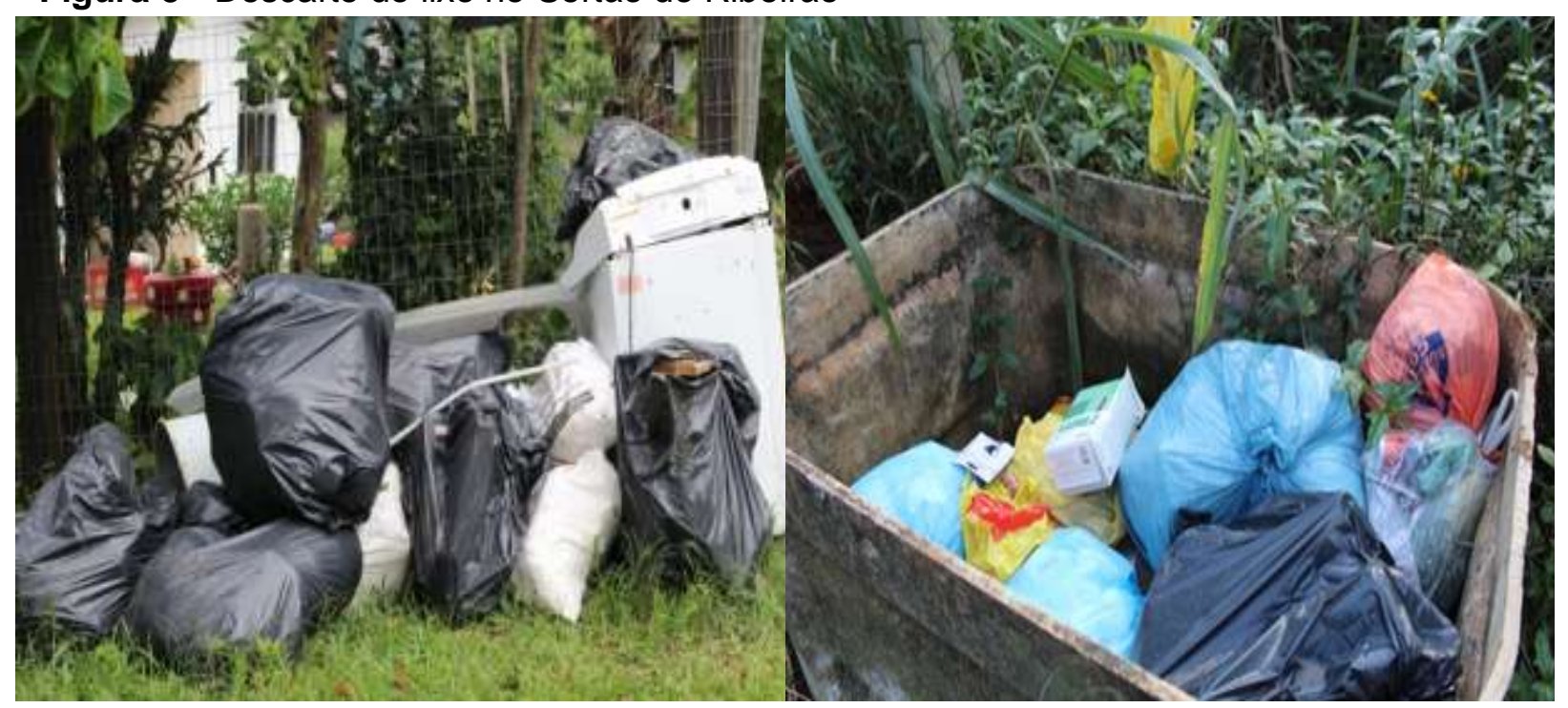

Fonte: Elaborado por Susana Barbosa (2018).

Figura 6 - Latões destinados a coleta de lixo no Sertão do Ribeirão
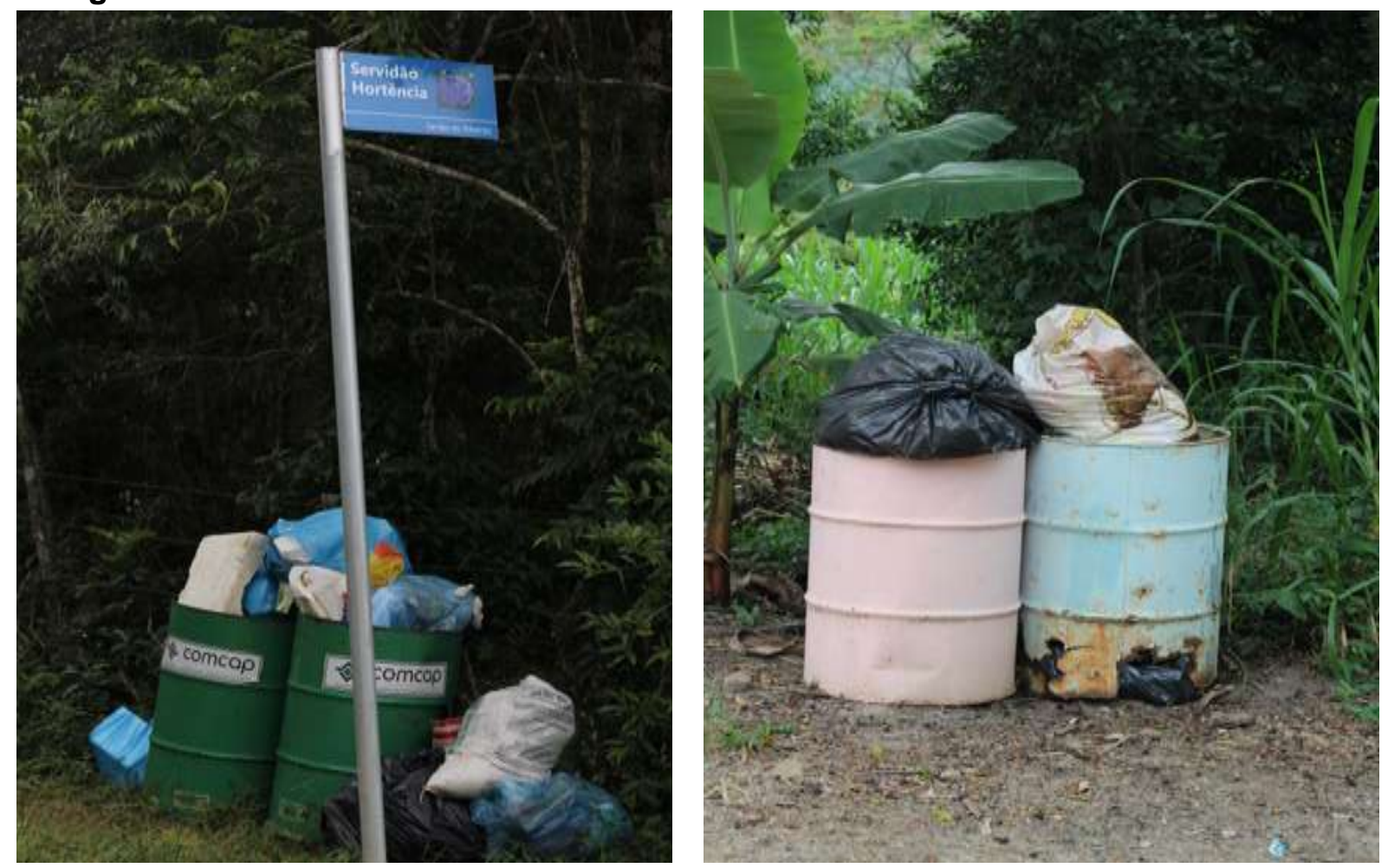

Fonte: Elaborado por Susana Barbosa (2018).

Durante dois meses, o grupo de estudantes percorreu a comunidade no intuito de observar o descarte do lixo. Junto às observações de campo, realizaram entrevistas com cinco lideranças locais. Ao longo dos trabalhos de campo, e a partir dos relatos coletados 
nas entrevistas, os estudantes conferiram que a coleta de lixo, de responsabilidade da Companhia de Melhoramentos da Capital (COMCAP), não estava sendo realizada adequadamente. Assim, vislumbravam na produção do curta-metragem um instrumento para fortalecer as reivindicações dos moradores da comunidade frente aos órgãos públicos.

A partir dos dados coletados em campo e apoiados na Lei 12.305 de 2010, a qual dispõe sobre a Política Nacional de Resíduos Sólidos (BRASIL, 2010), os estudantes estruturam um roteiro de vídeo. A ênfase do roteiro estava na importância da coleta e descarte adequado do lixo, uma vez que, do contrário, os resíduos produzidos e descartados incorretamente podem vir a contaminar os corpos d'água, lençóis subterrâneos e o solo, afetando diretamente a Lagoa do Peri e toda comunidade ali residente.

O curta-metragem Para onde vai o lixo? A luta da comunidade Sertão do Ribeirão na regularização da coleta, foi apresentado e partilhado com os funcionários do Departamento de Unidades de Conservação (DEPUC), do Departamento de Educação Ambiental (DEPEA), com lideranças locais da comunidade do Sertão do Ribeirão e com os estudantes da $3^{\underline{a}}$ e $7^{\underline{a}}$ fases do curso de Geografia da Universidade do Estado de Santa Catarina.

\section{CONSIDERAÇÕES FINAIS}

Os projetos de ensino desenvolvidos no Parque Municipal da Lagoa do Peri, a partir das atividades propostas pela disciplina de Estágio Curricular Supervisionado em Geografia III, abriram novas possibilidades de conhecimento para comunidade local e criaram novas perspectivas de intercâmbio acadêmico entre a Universidade e o Parque.

A saída de estudos na trilha do Caminho do Saquinho foi uma possibilidade metodológica de estudos geográficos que buscou incentivar a valorização da Área de Lazer do parque, além de suscitar pensar em espaços não formais de educação como laboratório de estudos ao ar livre. Já a produção e divulgação do curta-metragem sobre a problemática do lixo e dos resíduos sólidos foi um subsídio de estudos geográficos que contribuiu para despertar o interesse da comunidade do Sertão do Ribeirão para processos de gestão sustentável dos recursos, para elaboração de projetos que atendem as demandas dos moradores, e para o próprio empoderamento da população local diante da reivindicação de políticas públicas.

Portanto, em atividades como estas, assinalam-se práticas que permitem dimensionar as transformações espaciais do local, bem como seus conflitos e potencialidades, apontando para os modos como atualmente se perfaz a preservação do patrimônio natural e cultural. Ademais, trabalhos desta envergadura dão visibilidade à promoção de ações educativas de diferentes naturezas, bem como o incentivo à formação docente por meio do estágio supervisionado em unidades de conservação. 


\section{REFERÊNCIAS}

BRASIL. Lei Federal n. 12.305, de 02 de agosto de 2010. Institui a Política Nacional de Resíduos Sólidos; altera a Lei no 9.605, de 12 de fevereiro de 1998; e dá outras providências. Brasília, DF, Presidência da República, 2010.

BRASIL. Lei Federal n. 9.985, de 18 de julho de 2000. Regulamenta o art. 225, § 1으, incisos I, II, III e VII da Constituição Federal, institui o Sistema Nacional de Unidades de Conservação da Natureza e dá outras providências. Brasília, DF: Presidência da República, 2000.

CABRAL, L. O. Bacia da Lagoa do Peri: sobre as dimensões da paisagem e seu valor. Dissertação (Mestrado em Geografia). Universidade Federal de Santa Catarina, Florianópolis, 1999.

CABRAL, L.; BUSS, M. D. A paisagem como campo de visibilidade e de significação: um estudo de caso. Revista Espaço e Cultura. UERJ/ Rio de Janeiro. n. 13, p. 47-62, jan./jun. 2002.

CÂMARA, A. K. Territorialidade no Sertão do Ribeirão. A transformação da comunidade tendo em vista a mudança de seu território tradicional para Parque Municipal e a atual recategorização para Monumento Natural. 2018. Trabalho de Conclusão de Curso (Graduação em Geografia). Universidade do Estado de Santa Catarina, Florianópolis, 2018.

DEPUC - DEPARTAMENTO DE UNIDADES DE CONSERVAÇÃO. Parque Municipal da Lagoa do Peri. 2011. Disponível em: https://depuc.wordpress.com/2011/06/14/56/. Acesso em: 16 maio 2018.

FLORIANOPOLIS. Decreto Municipal n. 091, de 01 de julho de 1982. Regulamenta a Lei Municipal n. 1.828 de 04 de dezembro de 1981 que criou o Parque Municipal da Lagoa do Peri e instituiu seu Plano Diretor de ocupação e uso do solo. Florianópolis, 1982.

FLORIANOPOLIS. Lei Municipal n. 1.828, de 04 de dezembro de 1981. Cria o Parque Municipal da Lagoa do Peri e institui seu plano diretor de ocupação e uso do solo. Florianópolis: Câmara Municipal, 1981.

FLORIANÓPOLIS. Lei Municipal n. 10.530, de 02 de maio de 2019. Dispõe sobre a criação da unidade de conservação Monumento Natural Municipal da Lagoa do Peri (MONA da Lagoa do Peri). Florianópolis: Câmara Municipal, 2019.

IPUF - Instituto de Planejamento de Florianópolis. Plano Diretor do Parque da Lagoa do Peri. Florianópolis: IPUF, 1978.

KLEIN, R. M. Aspectos dinâmicos da vegetação do Sul do Brasil. Sellowia, Itajaí, v. 36, p. 554, 1984.

SBROGLIA, R. M.; BELTRAME, Â. da V. O zoneamento, conflitos e recategorização do Parque Municipal da Lagoa do Peri, Florianópolis/SC. Boletim de Geografia, Maringá, v. 30 , n. 1, p. 5-18, 2012.

STEPANSKI, E. Parque Municipal da Lagoa do Peri, em Florianópolis, é revitalizado para a temporada. Notícias do Dia, Florianópolis, 18 dez. 2014. Disponível em: 
https://ndonline.com.br/florianopolis/noticias/parque-municipal-da-lagoa-do-peri-de-caranova. Acesso em: 31 out. 2017.

Recebido: agosto de 2019. Aceito: outubro de 2019. 